\title{
A REFUSÃO EM FORNO ELÉTRICO A ARCO COMO PROCESSO DE RECICLAGEM DE CAVACOS DE ZIRCALOY
}

\author{
Pereira, L.A.T. ${ }^{1}$ Martinez, L.G. ${ }^{1}$; Rossi, J.L. ${ }^{1}$ \\ 1 CCTM - Centro de Ciência e Tecnologia de Materiais, IPEN - Instituto de Pesquisas Energéticas e Nucleares \\ - Cidade Universitária, 05508-000, São Paulo, SP, Brasil
}

\begin{abstract}
Resumo
O combustível nuclear usado em reatores de potência do tipo PWR é, geralmente, composto de pastilhas de dióxido de urânio $-\mathrm{UO}_{2}$, acondicionadas em tubos feitos de ligas de zircônio, chamados de encamisamento. As ligas de zircônio para aplicações nucleares são estratégicas e controladas sob salvaguardas sob o ponto de vista de tecnologia nuclear, econômico e ambiental. Por isso, além de seu custo elevado, estas ligas de zircônio de grau nuclear, ou seja, isentas de háfnio, não são comercializadas livremente. Na sua fabricação são gerados cavacos de usinagem que não podem ser descartados, pelas razões expostas acima. As ligas nucleares têm altíssimo custo e não são produzidas no Brasil, sendo importadas para a fabricação do combustível nuclear. Neste trabalho os cavacos foram fundidos utilizando um forno elétrico a arco para obter lingotes. A composição química, as fases presentes e a dureza no material foram determinadas. Os lingotes foram tratados termicamente e laminados, sendo que as microestruturas foram caracterizadas por microscopia óptica. Os resultados mostraram que a composição do Zircaloy reciclado cumpre as especificações químicas e apresentaram microestruturas adequadas para uso nuclear.
\end{abstract}

Palavras chaves: Fusão a arco elétrico; Zircaloy; reciclagem; combustível nuclear; encamisamento.

1. INTRODUÇÃO

As pastilhas de $\mathrm{UO}_{2}$ do combustível nuclear dos reatores de potência do tipo PWR são geralmente acondicionadas em tubos feitos de ligas de zircônio, chamados de encamisamento (cladding), conhecidas como Zircaloys. Tanto o encamisamento como os demais componentes estruturais (grades e guias) dos elementos combustíveis estão expostos a ambientes de água em alta pressão e alta temperatura. Além disso, por integrarem o núcleo do reator, há a necessidade de que esses materiais tenham baixa seção de choque de absorção para nêutrons térmicos.

As ligas à base de zircônio atendem esses requisitos devido às excelentes propriedades mecânicas e de resistência à corrosão. Estas propriedades são obtidas devido ao baixo teor de háfnio nas ligas e às composições químicas e microestruturas adequadas. As ligas mais comuns são denominadas Zircaloy-2, Zircaloy-4, Zirlo® e M5®, cujas composições elementares são mostradas estão mostradas na TAB. 1.

Cada vareta é fechada em suas extremidades por um tampão, também confeccionado em Zircaloy, o qual é produzido a partir de barras maciças do metal. Durante a fabricação desse componente são geradas grandes quantidades de cavacos, resultantes da usinagem das peças em tornos mecânicos automáticos. Os cavacos de Zircaloy são uma valiosa fonte para o reaproveitamento de zircônio. Trabalho recente de Collins et al. com a recuperação de $Z r$ em elementos combustíveis queimados avalia o valor do zircônio nessas condições entre US\$ 40-80/kg [1], uma vez que o metal Zr é o principal constituinte da liga Zircaloy, tendo a grande vantagem de ser isento de $\mathrm{Hf}$ [2].

Este trabalho teve como objetivo desenvolver processos de reciclagem de cavacos de usinagem da liga Zircaloy-4, resultantes da fabricação de componentes de elementos combustíveis, propondo e aperfeiçoando uma tecnologia de reaproveitamento dos cavacos de Zircaloy por refusão em forno elétrico a arco. O trabalho objetivou também a caracterização química, física e microestrutural do material resultante, com e sem tratamentos termomecânicos.

\section{MATERIAIS E MÉTODOS}




\section{Workshop of Applied Crystallography to \\ Materials Science and Engineering}

\section{Blucher}

TABELA 1 - Composições típicas das ligas Zircaloy-2, Zircaloy-4, Zirlo e M5 [2][3][4][5].

\begin{tabular}{lllllllll}
\hline $\begin{array}{l}\text { Elemento } \\
\text { (\% massa) }\end{array}$ & Sn & $\mathbf{F e}$ & $\mathbf{C r}$ & $\mathbf{N i}$ & $\mathbf{0}$ & $\mathbf{H f}$ & $\mathbf{Z r}$ & $\mathbf{N b}$ \\
\hline Zircaloy-4 & $1,2-1,7$ & $0,18-0,24$ & $0,07-0,13$ & - & 0,12 & $<1000 \mathrm{ppm}$ & balanço & - \\
\hline Zirlo ${ }^{\circ}$ & $0-0,99$ & 0,11 & - & - & 0,11 & $40 \mathrm{ppm}$ & balanço & 0,98 \\
\hline M5 ${ }^{8}$ & $<30 \mathrm{ppm}$ & 0,03 & $40 \mathrm{ppm}$ & - & $0,14-0,15$ & - & balanço & 1,00 \\
\hline
\end{tabular}

Zirlo® e M5 $\circledast$ são marcas registradas da Westinghouse Electric Company e AREVA NP.

\section{1- Tratamento dos cavacos de Zircaloy-4}

A matéria-prima do Zircaloy-4 para este trabalho foi fornecida na forma de cavacos. O tratamento realizado constou de uma etapa inicial de limpeza do material, seguida pela prensagem dos cavacos [6], a qual teve como objetivo acomodar adequadamente os cavacos nas canaletas no forno VAR (Vacum Arc Remelting), a fim de evitar a dispersão dos mesmos com o arco elétrico durante a fusão.

2.2 Fusão dos cavacos de Zircaloy

O equipamernto utilizado para a fusão dos cavacos é um forno a arco elétrico com eletrodo não consumível

\section{3- Laminações}

Após a fusão as amostras foram submetidas a um tratamento termo-mecânico, o qual constou de um recozimento a $850^{\circ} \mathrm{C}$ e $950^{\circ} \mathrm{C}$, seguido de laminação a quente. A fim de evitar a oxidação do material nos tratamentos térmicos, estas amostras foram encapsuladas em tubos de cobre. Na FIG. 1 mostra-se o aspecto das barras fundidas de Zircaloy-4.

FIGURA 1 - Barras de Zircaloy-4 obtidas na fusão destinadas à tratamento térmico e laminação.

\section{4- Preparação e análise metalográfica}

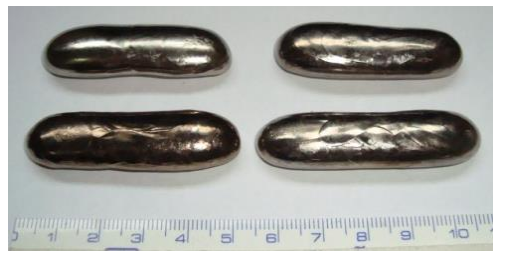

As amostras fundidas foram cortadas com disco diamantado de precisão e embutidas em resina de poliester de cura a frio, sendo submetidas ao lixamento em lixas de SiC até a grana 4000, seguido de polimento em pastas diamantadas de $6 \mu \mathrm{m}$ e $1 \mu \mathrm{m}$, com finalização em sílica coloidal. O ataque foi realizado com uma solução de $50 \% \mathrm{H}_{2} \mathrm{O}_{2}$ $+25 \% \mathrm{HNO}_{3}+25 \%$ álcool etílico +2 gotas HF [7]. As análises de metalografia foram executadas através de microscopia óptica.

\section{5- Dureza}

A medição de dureza foi efetuada com a escala da dureza Rockwell B (HRB). Nas amostras da fusão \#10 foram realizadas medições de dureza ao longo da seção transversal e longitudinal após a laminação, a fim de verificar a ocorrência da anisotropia da dureza devido à conformação.

\section{6- Difração de raios $X$}

As medidas de difração de raios $X$ foram realizadas em um difratômetro com goniômetro de geometria teta-teta de raio 285 mm, monocromador de grafite pirolítico, detetor de cintilação, utilizando radiação Cuka à tensão de 40 kV e corrente de $30 \mathrm{~mA}$. Para a análise por difração de raios $X$ as amostras obtidas por fusão foram preparadas por lixamento das superfícies até a grana 1200 [8][Ptech]

\section{RESULTADOS E DISCUSSÃO}

3.1- Análise química

Na TAB. 2 são apresentados os valores da especificação para o Zircaloy-4, os valores certificados do padrão CRM 098 [7] e os valores determinados por fluorescência de raios X para o padrão CRM 098 e para os cavacos de Zircaloy-4. Os valores certificados e medidos do padrão CRM 098 foram usados para a calibração do método.

$\mathrm{Na}$ TAB. 3 são apresentados os resultados de composição química determinados por fluorescência de raios $X$ das amostras obtidas na fusão. A análise química das amostras contida na TAB. 3, revelou que todos os elementos que compõem a liga estão dentro da especificação, com exceção do Fe que está acima do especificado, indicando que houve contaminação da liga por esses elementos durante o processo de fusão, devido estarem misturados com cavacos de aço.

\section{2- Metalografia}


TABELA 2 - Análise química do Zircaloy-4 (na forma de cavacos) e do padrão.

\begin{tabular}{llll}
\hline \hline $\begin{array}{l}\text { Elemento } \\
\text { (\% massa) }\end{array}$ & $\begin{array}{l}\text { CRM 098 } \\
\text { Valores certificados }\end{array}$ & $\begin{array}{l}\text { CRM 098 } \\
\text { Valores determ. }\end{array}$ & $\begin{array}{l}\text { Zry-4 Cavacos } \\
\text { Valores determ. }\end{array}$ \\
\hline $\mathbf{C r}$ & $0,0906 \pm 0,009$ & $0,088 \pm 0,003$ & $0,080 \pm 0,010$ \\
\hline $\mathbf{F e}$ & $0,2143 \pm 0,002$ & $0,210 \pm 0,006$ & $0,213 \pm 0,036$ \\
\hline $\mathbf{S n}$ & $1,460 \pm 0,009$ & $1,42 \pm 0,15$ & $1,246 \pm 0,102$ \\
\hline $\mathbf{Z r}$ & - & $98,30 \pm 0,15$ & $98,43 \pm 0,06$ \\
\hline
\end{tabular}

TABELA 3 - Análise química do Zircaloy-4 obtido na fusão e os valores de especificação.

\begin{tabular}{lll}
\hline \hline $\begin{array}{l}\text { Elemento } \\
\text { \% massa) }\end{array}$ & $\begin{array}{l}\text { Amostra fundida } \\
\text { Valores Determ. }\end{array}$ & Zry-4 especif. [3] \\
\hline $\mathrm{Cr}$ & $0,066 \pm 0,003$ & $0,07-0,13$ \\
\hline $\mathrm{Fe}$ & $0,340 \pm 0,030$ & $0,18-0,24$ \\
\hline $\mathrm{Sn}$ & $1,110 \pm 0,030$ & $1,2-1,7$ \\
\hline $\mathbf{Z r}$ & $98,45 \pm 0,010$ & \\
\hline
\end{tabular}

Na FIG. 3 é mostrada a microestrutura típica de uma amostra antes do tratamento térmico e na FIG. 4 é apresentada a micrografia óptica de uma amostra aquecida segundo uma das temperaturas e esquemas de laminações mencionados no item 2.3.

$\mathrm{Na}$ micrografia da amostra laminada a $850{ }^{\circ} \mathrm{C}$, mostrada na FIG. 4, observa-se características de microestrutura Widmanstätten. Antes da laminação as fibras tinham um arranjo do tipo paralelo, com comprimentos entre $80 \mu \mathrm{m}$ e $100 \mu \mathrm{m}$, conforme mostrado na FIG. 3. Após a laminação, elas tomaram a configuração Widmanstätten basketweave com fibras menores e mais finas, medindo entre 40 e $60 \mu \mathrm{m}$ e aproximadamente $5 \mu \mathrm{m}$ de espessura.

FIGURA 1 - Microscopia óptica da amostra antes do tratamento térmico, onde pode-se observar ripas da fase $\alpha$ paralelas.

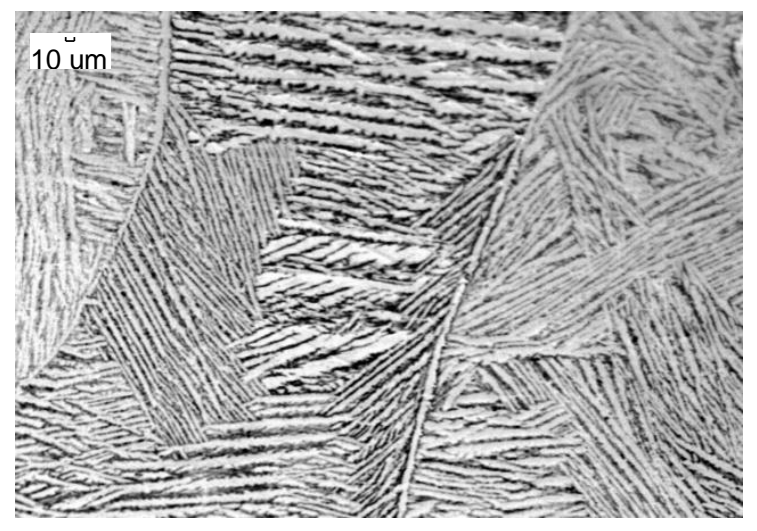

\subsection{Dureza}

Na TAB. 20 são apresentados os valores de dureza Rockwell B medidos nas amostras da fusão \#10, depois do tratamento termo-mecânico. A fim de conhecer a evolução da dureza com o tratamento termo-mecânico, foi medida a dureza da amostra 10.3 antes da laminação e tomada como referência para as amostras 10.1 e 10.2.

\subsection{Difração de raios $X$}

Na FIG. 5 é apresentado o difratograma de raios $X$ de uma amostra após a fusão plotado com os dados ajustados utilizando o programa Powder Cell. Além da identificação das fases, o ajuste também fornece os índices dos planos difratados e os valores dos parâmentros de rede. A difração de raios $X$, como pode ser observado na figura revelou somente a presença do $\mathrm{Zr}$, devido ao fato do teor dos outros elementos químicos na liga ser baixa e manter a estrutura do Zircaloy.

\section{CONCLUSÕES}

Observando as análises químicas realizadas nas amostras recicladas por fusão, pode-se concluir que a composição de partida da liga Zircaloy manteve-se no material reciclado. É possível concluir que os cavacos fornecidos pela INB continham resíduos de aço que elevaram os teores Fe e Cr. Através das análises microestruturais dos materiais reciclados pode-se concluir que as ligas apresentaram as morfologias típicas do Zircaloy. Quanto aos estudos sobre laminação, os materiais atendem às condições requeridas ao processamento termo-mecânico.

Finalmente, este estudo demonstrou a viabilidade da reciclagem de cavacos de usinagem de Zircaloy por refusão em forno elétrico a arco em termos de propriedades adequadas e processamento termo-mecânico. 
FIGURA 4 - Microscopia óptica da amostra após o tratamento termo-mecânico a $850{ }^{\circ} \mathrm{C}$ e laminação a quente, com morfologia característica de estrutura Widmanstätten da forma basketweave.

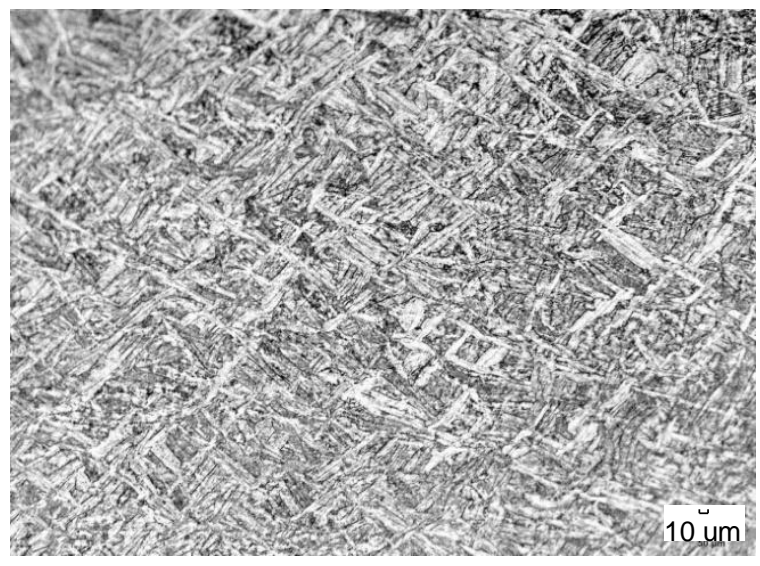

TABELA 2 - Dureza HRB das amostras medidos antes e após a laminação, nas direções transversal e longitudinal.

\begin{tabular}{llll}
\hline \hline Amostra & $\mathbf{1 0 . 1}$ & $\mathbf{1 0 . 2}$ & $\mathbf{1 0 . 3}$ \\
\hline Antes da laminação (HRB) & $93,0 \pm 0,5$ & $93,0 \pm 0,5$ & $93,0 \pm 0,5$ \\
\hline Laminação transversal (HRB) & $103,3 \pm 0,4$ & $89,7 \pm 4,4$ & $96,4 \pm 2,3$ \\
\hline Laminação longitudinal (HRB) & $105,7 \pm 0,5$ & $92,8 \pm 0,7$ & $98,2 \pm 0,2$ \\
\hline
\end{tabular}

FIGURA 5 - Refinamento de dados de difração de raios $\mathrm{X}$ da amostra de Zircaloy-4 obtido por fusão a arco. Os parâmetros de rede ajustados e o resíduo de refinamento são mostrados na figura, indicandose a fase encontrada: $\mathrm{Zr}$.

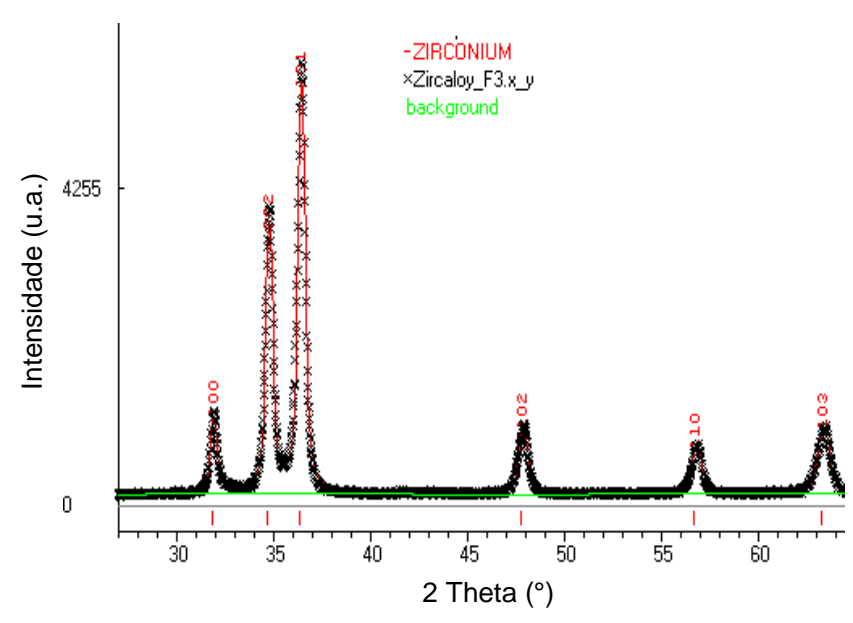

5. AGRADECIMENTOS

Os autores agradecem à CNEN (Comissão Nacional de Energia Nuclear) pela bolsa de doutorado de Luiz Alberto Tavares Pereira.

6. REFERÊNCIAS

1 COLLINS, E.D.; DELCUL, G.D.; et al. Process development studies for zirconium recovery/recycle from used nuclear fuel cladding. Procedia Chemistry, v. 7, p. 72-76, 2012.

2 BOHE, A.E.; ANDRADE GAMBOA, J.J.; LOPASSO, E.M.; PASQUEVICH, D.M. Zirconium recovery from Zircaloy shavings. J. Mater. Sci., v. 31, p. 3469-3474, 1996.

3 Standard specification for hot-rolled and cold-finished zirconium and zirconium alloy bars, rod, and wire for nuclear application. ASTM: B351-08. ASTM-AMERICAN SOCIETY FOR TESTING AND MATERIALS.,

4 YILMAZBAYHAN, A.; A.; MOTTA, A.T.; et al. Structure of zirconium alloy oxides formed in pure water studied with synchrotron radiation and optical microscopy: relation to corrosion rate. Journal of Nuclear Materials, v. 324, n. 1, p. 622, 2004.

5 DURIEZ, C..; DUPONT, T.; et al. Zircaloy-4 and $\mathrm{M} 5 \AA$ high temperature oxidation and nitriding in air. Journal of Nuclear Materials, v. 380, n. 1-3, p. 30-45, 2008.

6 PEREIRA, L.A.T. Desenvolvimento de processos de reciclagem de cavacos de zircaloy via refusão em forno elétrico a arco e metalurgia do pó. Instituto de Pesquisas Energéticas e Nucleares - IPEN. Tese (Doutorado), 2014. 7 VOORT, G.F. VANDER Metallography - Principles and Practice. ASM International, 1999.

8 Takiishi, H.; Duvaizen, J.H.; et al. Recycling of Zircaloy Machining Chips by VAR Remelting and Powder Metallurgy Techniques. Materials Science Forum, v. 727-728, p. 356-361, 2012. 